\title{
Psychopathy and free will from a philosophical and cognitive neuroscience perspective
}

CHAPTER · SEPTEMBER 2015

DOI: $10.1017 / C B 09781139565820.007$

3 AUTHORS, INCLUDING:

\section{Farah Focquaert}

Ghent University

30 PUBLICATIONS 139 CITATIONS

SEE PROFILE
Andrea L Glenn

University of Alabama

40 PUBLICATIONS 1,123 CITATIONS

SEE PROFILE 


\title{
6 Psychopathy and free will from a philosophical and cognitive neuroscience perspective
}

Farah Focquaert, Andrea L. Glenn, and Adrian Raine

\begin{abstract}
In our chapter, we discuss one of the most influential compatibilist accounts of free will, Fischer and Ravizza's (1998) reasonsresponsiveness theory, and review the empirical literature on psychopathy that addresses the requirements for moral responsibility that are put forward in their account. Reasons-responsive compatibilist views seem to argue for the absence of moral responsibility or at least diminished responsibility when considering psychopathy. Their view draws upon impairments in the relevant kind of reasons-responsiveness in which one is responsive to both prudential and moral reasons. If moral reasons as genuine reasons that may motivate behavior are somehow alien to individuals with psychopathy, can we argue that these individuals are fully responsible for their immoral behavior? Based on empirical findings, we argue that psychopaths have core affective and cognitive deficits that may impair moral rationality. We conclude that the hard determinist, hard incompatibilist, and reasons-responsive compatibilist view suggest that offenders with severe psychopathy should not be held criminally responsible, and that mild psychopathy should function as a mitigating factor allowing for partial criminal responsibility. We should greatly increase our emphasis on early prevention and rehabilitation while ensuring that society is adequately protected and the feelings and rights of victims are respected.
\end{abstract}

What we fear - or at any rate a very important part of what we fear - in determinism is the prospect that determinism would rule out control, and we very definitely do not want to lose control or be out of control or be controlled by something or someone else - like a marionette or puppet.

(Dennett, 1984: 51) 


\section{Introduction}

Psychopathy is a personality disorder that is characterized by a combination of personality and behavioral features. The interpersonal and affective features encompass specific personality traits such as glibness, deceitfulness, conning, superficial charm, manipulativeness, and a lack of empathy, guilt, or remorse. In addition to reactive aggression, psychopaths also uniquely show instrumental (unprovoked) aggression. In the USA, about 20-25 percent of prisoners would be considered psychopaths as measured by the Psychopathy Checklist-Revised (PCL-R). Psychopathic traits are considered one of the strongest predictors of violent recidivism. Research studies have had little success in identifying behavioral treatment programs that work in adult psychopaths.

A growing body of evidence has begun to identify both genetic and environmental factors that appear to contribute to the development of psychopathic traits and demonstrate that regions of the brain function differently in these individuals. This research raises many questions for our concept of free will and moral/criminal responsibility. In this chapter, we briefly review philosophical theories concerning the relationship between free will and moral responsibility. On one hand, hard determinists and hard incompatibilists argue that free will is incompatible with a scientific worldview (i.e., knowledge provided by our best scientific theories) and therefore argue that free will is an illusion. If free will is an illusion, then no individual, including a psychopath, can be held responsible for his or her behavior because moral responsibility presupposes free will. Moreover, according to hard determinists and hard incompatibilists, knowledge about the genetic or neurobiological factors that contribute to deviant behavior is irrelevant to the debate on responsibility since no individual, regardless of genetic or neurobiological makeup, can be held responsible. For example, a hard determinist may argue that both the psychopath's and the non-psychopath's behavior is " $100 \%$ determined by brain function, which is in turn determined by the interplay of genes and experience" (Farah, 2005: 38). On these views, the answer to criminal offenders with psychopathy and the potential threat to public safety may lie in non-punitive measures that aim to protect society and its members from harm. For example, some defend a consequentialist, deterrence-based view of incarceration aimed not at punishing psychopaths but preventing them from causing further harm to others, while others argue for the development of innovative and benign biosocial programs for crime prevention (Glenn \& Raine, 2014). Compatibilists, on the other hand, argue that free will, and thus moral responsibility, is compatible with a scientific worldview. Compatibilist theories on the 
relationship between free will and moral responsibility specify the requirements that are necessary for holding an individual morally responsible. Compatibilists may argue that the ability for reasons-responsive behavior enables free behavior and thus moral responsibility. If psychopaths can be said to have the ability for reasons-responsive behavior, then these individuals are morally responsible and may be held criminally responsible and punished. If they are not responsible because they are impaired in or lack the capacity for reasons-responsive behavior, then it is this impairment, not causal determinism, that explains why they are not responsible.

In this chapter, we discuss one of the most influential compatibilist accounts on free will, Fischer and Ravizza's (1998) reasonsresponsiveness theory, and review the empirical literature on psychopathy that addresses the requirements for moral responsibility that are put forward in their account. Based upon the literature, we will discuss whether psychopaths can be considered reasons-responsive individuals. Reasons-responsive compatibilist views seem to argue for the absence of moral responsibility or at least for diminished responsibility when considering psychopathy, due to the absence of the relevant kind of reasons-responsiveness that is necessary for moral responsibility (i.e., responsiveness to prudential and moral reasons). If moral reasons as genuine reasons that may motivate behavior are somehow alien to individuals with psychopathy, can we argue that these individuals are (fully) responsible for their immoral behavior? Based on empirical findings, we argue that psychopaths have core affective deficits, as well as cognitive deficits that may (partially or fully) impair moral rationality. We conclude that the hard determinist, hard incompatibilis, and reasons-responsive compatibilist view suggest that offenders with severe psychopathy should not be held criminally responsible, and that mild psychopathy should function as a mitigating factor allowing for partial criminal responsibility (as in the Netherlands).

\section{Incompatibilist and compatibilist accounts of free will}

Free will can be defined as "the unique ability of persons to exercise control over their conduct in the fullest manner necessary for moral responsibility" (McKenna, 2009), or alternatively, and somewhat less circular, as "the ability of persons to exercise full control over their conduct." The philosophical debate on free will is concerned with the notion of moral responsibility and the knowledge or presupposition that we need a concept of voluntary control/behavior (i.e., free will) in order to justify its use: "it is a presupposition that some sort of control is a 
necessary condition of morally responsible agency" (Fischer \& Ravizza, 1998: 20). The crucial question, then, seems to be which kind of control is required for us to hold others morally responsible. Does it imply that I, as an agent, could have acted differently or that I have ultimate control over my behavior? And how does causal determinism come into play?

Causal determinism can be defined as "the metaphysical thesis that facts of the past, in conjunction with the laws of nature, entail every truth about the future" (McKenna, 2009). According to incompatibilists (i.e., libertarians, hard determinists, and hard incompatibilists), free will is not compatible with causal determinism (e.g., Clarke, 2000; Greene \& Cohen, 2004; Kane, 1999; Wegner, 2002). Libertarians argue that because at least certain individuals behave freely and are responsible for at least some of their behavior, causal determinism must be false. They argue that the alternatives to causal determinism enable free will (e.g., the possibility of ontological indeterminacy in classical mechanics and/or the claim of ontological indeterminacy in quantum mechanics extending from the micro-level of atoms to the macro-level of human decisionmaking). The concepts of acausality (events that happen without a distinct cause), and/or autocausation (events that happen without an external cause) are invoked to allow for free will. Hard determinists argue that free will is an illusion due to the causal deterministic processes that are at work. Hard incompatibilists argue that both causal determinism and indeterminism (e.g., quantum physics) pose a threat to free will. According to hard determinists and hard incompatibilists, to have full control over one's conduct implies that an individual has the ability to act differently at a given point in time (i.e., has alternative possibilities), and/ or that an individual can be considered the ultimate source of his or her actions (i.e., meaning that one's actions originate in oneself). This means that if at any point in time we could not have acted differently, and/or we cannot be considered the ultimate source of our own actions, then we cannot be held responsible for our behavior. Causal determinism rules out freedom of alternatives and ultimate source control, because it implies that any action we perform at a particular time is the only action we could have performed at that time and because it implies that the mental states that issue in our actions are causally determined by antecedent events (Glannon, 2011).

If one holds the position that neither causal determinism nor indeterminism provides an individual with free will in the relevant sense, then our current knowledge about the neurobiology of psychopathy, or any other psychiatric conditions, is irrelevant to moral responsibility. The hard incompatibilist view, which argues that neither determinism nor indeterminism give us the right kind of free will, basically entails that no 
individual has the right kind of free will or freedom to be held morally responsible. Hence, what the brain science tells us about the brain of the psychopath and how normal or abnormal the psychopath's brain might be is basically irrelevant. In a world without alternative possibilities, or without ultimate source control, no individual can be held responsible (in a scientifically relevant sense at least). Whether one wishes to hold individuals responsible based on reasons other than purely scientific considerations (e.g., the pragmatic value of having a notion of moral responsibility) is a different matter. For example, Dennett (2003) argues that "the fact that free will is worth wanting can be used to anchor our conception of free will" (p. 297). The pragmatic value of having a notion of moral responsibility raises questions about the relevance of the deterministic view for normative judgments of individuals' behavior. If no one has free will and no one can be held morally responsible due to biological and environmental factors that are beyond our control, then there seems to be no way of differentiating between an individual who can control his or her behavior and an individual who cannot (e.g., violent offender). Compatibilists disagree with incompatibilists with regard to the kind of free will that is required for moral responsibility. According to many compatibilists, moral responsibility does not presuppose alternative possibilities, nor does it presuppose ultimate source control. Moreover, unlike libertarians, the kind of control that compatibilists typically put forward as the required condition for morally responsible agency does not presuppose acausality or autocausation. Hence, they will typically defend a type of control that is compatible with a causally closed deterministic universe. For example, many compatibilists argue that having control over one's behavior implies that an agent plays a crucial role in the production of his or her actions, or put differently, that one's actions issue from one's self in a suitable manner (McKenna, 2009). Fischer and Ravizza (1998) distinguish regulative control from guidance control. Regulative control implies that an agent has the ability to regulate between different alternatives (which brings us back to the "alternative possibilities" demand), whereas guidance control implies that an agent guides or brings about his or her conduct (in a suitable manner) even if he or she has no other alternatives to the course he or she takes. Regulative control implies a dual type of control in which the agent has the power both to act freely (i.e., guidance control) and to do something else instead (Fischer \& Ravizza, 1998).

To convince non-compatibilists, philosophers defending regulative control must show what is wrong with the consequence argument. The consequence argument claims that since (a) no one has power over the facts of the past and the laws of nature, and (b) no one has power over 
the fact that the facts of the past and the laws of nature entail every fact of the future (i.e., causal determinism is true), we can conclude that (c) no one has power over the facts of the future (see McKenna, 2009). The consequence argument shows that an individual does not have alternative options available within a causally determined world. Interestingly, Frankfurt devised a thought experiment that questions the need for alternative possibilities when one attributes moral responsibility to others (see Frankfurt, 1969). McKenna (2000: 92) gives the following Frankfurt-type example:

Sam plans to kill the major and carries out his plan without any interference from "outside forces." Unbeknownst to Sam, Jack, a mad neurologist, wants Sam to kill the mayor and would prefer that Sam did it on his own. But, worried that Sam will change his mind, Jack implants a device in Sam's brain which allows Jack to monitor Sam's brain activity from afar. Should Sam give any indication to Jack that he (Sam) will do other than kill the mayor, Jack will activate his otherwise dormant device, bringing it about that Sam kills the major. But, as things go, Sam kills the mayor on his own. Jack never intervenes.

According to Frankfurt and others (e.g., Fischer \& Ravizza, 1998; McKenna, 2009), the natural reaction to this type of scenario is to claim that Jack, even though he could not have acted differently, is nevertheless morally responsible for his behavior. This seems to imply that moral responsibility does not rely on the "freedom to do otherwise" (i.e., alternative possibilities), but rather on the capacity 'to act freely' (i.e., having the right kind of control over one's actions). Following Frankfurt, most compatibilists focus on the issue of control rather than alternative possibilities, and many argue that what is necessary for moral responsibility (and the type of free will that is required to hold someone responsible) is guidance control rather than regulative control. Unlike regulative control, guidance control is compatible with determinism.

\section{Reasons-responsive compatibilism}

Compatibilists like Wolf (1990), and Fischer and Ravizza (1998) argue that to have control over one's conduct (i.e., guidance control) and thus have the capacity for moral responsibility implies that an individual has the ability for reasons-responsive behavior. Reasons-responsiveness generally entails that individuals who are unresponsive to a range of rational considerations do not act of their own free will (e.g., individuals with OCD or schizophrenia), whereas agents who are responsive to a range of rational considerations do act of their own free will. Reasonsresponsiveness gives rise to moral responsibility by locating "the control required for morally responsible agency in the capacity to respond to 
reasons for action" (McKenna, 2000: 89). For example, Fischer and Ravizza (1998) claim that moral responsibility does not entail the freedom to do otherwise. According to them, another type of freedom is required for the attribution of moral responsibility. They defend a semicompatibilist account, in which determinism is incompatible with the freedom to do otherwise, but compatible with moral responsibility. On their account, guidance control refers to "the power to perform an action freely," whereas regulative control refers to "the power to perform an action freely" as well as the "power to act otherwise" (McKenna, 2000: 91). This difference is important according to Fischer and Ravizza because although determinism rules out alternative possibilities, it doesn't rule out a different kind of freedom, namely the freedom that falls under guidance control. What appears to be relevant in the Frankfurt-type examples, according to Fischer and Ravizza (1998) is whether or not Sam's actions result from a "mechanism which is reasons-responsive" (McKenna, 2000: 95). Rather than focusing on whether or not the agent is reasons-responsive, we need to discover if the mechanism that actually issues in the action (i.e., the action-sequence mechanism) is reasons-responsive. In the Frankfurt-type case, although Sam himself cannot be considered reasons-responsive (due to the implanted device that would take control if he did not kill the mayor on his own), he can nevertheless be considered morally responsible because his actions result from a mechanism that is reasons-responsive. To ascribe moral responsibility, we need to detect whether or not, in the actual sequence of events, the agent exhibited the right kind of control (i.e., based upon the presence of a mechanism which is reasonsresponsive). In their moderately reasons-responsive mechanism account, Fischer and Ravizza (1998) draw a difference between "receptivity to reasons" on the one hand, and "reactivity to reasons" on the other hand. Receptivity to reasons implies that the agent recognizes those reasons that are captured by "intuitively plausible conditions of rationality" (McKenna, 2000: 97):

In judging a mechanism's receptivity, we are not only concerned to see that a person acting on that mechanism recognizes a sufficient reason in one instance; we also want to see that the person exhibits an appropriate pattern of reasonrecognition. In other words, we want to know if he recognizes how reasons fit together, sees why one reason is stronger than another, and understands how the acceptance of one reason as sufficient implies that a stronger reason must also be sufficient. (Fischer \& Ravizza, 1998: 70-71)

Reactivity to reasons involves the capacity to translate reasons into choices and subsequent behavior. However, whereas regular receptivity to reasons is required, only weak reactivity to reasons is required on their 
account (Fischer \& Ravizza, 1998). This means that an individual has to have the capacity or "cognitive power" to recognize actual incentives to do otherwise on a regular basis, but only has to display some reactivity to reasons in order to show that he or she has the "executive power" to react to an actual incentive to do otherwise. For example, if an addict is not able to give up his or her addictive behavior based upon rational reasons related to health and wellbeing (i.e., health-related incentives), but is able to give up his or her addictive behavior if the price of the addictive substance goes up (i.e., market-related incentives), then this individual exhibits weak reactivity to reasons and thus can be held morally responsible for not acting upon health-related incentives to quit his or her addiction. Or, for example, if a heroine-addicted female cannot give up her addiction for her own health and wellbeing, but can abstain from taking heroine when she discovers that she's pregnant, then, according to Fischer and Ravizza, she can be held morally responsible for her behavior at other times (before or after her pregnancy). Fischer and Ravizza (1998) explain their position on weak reactivity as follows: "That is, we believe that if an agent's mechanism [= process that leads up to an action] reacts to some incentive to (say) do other than he actually does, this shows that the mechanism can react to any incentive to do otherwise" (p. 73). We do not discuss the scientific validity of their view, but there does remain a lively debate as to whether or not the human (addicted) brain indeed functions in such a way (Kennett, 2010). Finally, Fischer and Ravizza (1998) argue that the kind of reasons-responsiveness that is required for moral responsibility needs to be categorized as a responsiveness to a range of reasons, including (some, but not necessarily all) moral reasons. On Fischer and Ravizza's (1998) view, some psychopaths can be considered morally responsible agents whereas others cannot. They argue that a psychopath who is not capable of recognizing that he or she has reasons for action deriving from other individuals' rights or interests has an impaired receptivity to moral reasons and cannot be held morally responsible. A psychopath who has an appropriate receptivity to moral reasons can be held morally responsible. The inclusion of moral reasons is important because it has been argued that severe psychopaths are unresponsive to moral reasons (Morse, 2008), whereas offenders with lesser psychopathy may be partly impaired in terms of their responsiveness to moral reasons (Morse, 2011a). On this view, the ability or inability to respond to moral reasons is a matter of degree and should be understood on a continuum involving degrees of impaired responsiveness.

In sum, if one argues that having full control over one's conduct implies having the ability for reasons-responsive behavior, then 
individuals do have free will and can be held morally responsible for their behavior. Therefore, within the compatibilist universe sketched above, we need to ask ourselves whether psychopaths are reasons-responsive individuals. Can empirical studies on psychopathy help us in answering these questions? Psychopaths appear to have the capacity to choose in accord with their mental states since it is commonly argued that these individuals do possess cognitive rational capacities. At the same time, these individuals appear to lack moral rational capacities, as has been suggested by Stephen Morse (2008), and as can be argued when considering the neurobiological impairments in individuals with psychopathy. This means that although psychopaths may be able to respond to prudential rational reasons, they are likely unable to respond to moral rational reasons. Hence, it can be argued that these individuals, depending on the severity of their disorder, may not be fully responsible.

\section{Empirical research on psychopaths}

Psychopaths have an intellectual understanding that society has standards for which actions are acceptable and which actions are not. For example, a psychopath can acknowledge that it is illegal to steal. However, research examining how psychopaths respond to various types of stimuli suggests that they lack responsiveness to reasons that nonpsychopathic individuals rely upon when making decisions in the moral domain. These deficits include the following:

The inability to take the perspective of another and feel concern for his or her suffering

Several studies have found that psychopaths have deficits in this domain at various levels. At the most basic level, both children and adults with psychopathic traits show deficits in recognizing facial expressions of fear in other individuals (Blair et al., 2001; Blair et al. 2004), thus limiting their ability to recognize when another individual is in distress. Similarly, they demonstrate an impairment in recognizing fearful vocal affect (Blair et al., 2005). The consequences of these deficits can be seen in a recent study of youth with psychopathic traits, which found that these children are less likely to expect that aggression will result in a victim suffering and are less likely to expect that they will experience feelings of remorse (Pardini \& Byrd, 2012). Like adults with psychopathic traits (Glenn et al., 2009a), they report lower levels of empathetic concern and lower levels of sadness in response to others' distress. 
The identification of deficits in the recognition of fearful facial expressions and vocalizations parallels findings from patients with damage to the amygdala (e.g., Adolphs et al., 1999), a region of the brain involved in emotional processing. Indeed, brain imaging studies indicate that psychopathic individuals have structural and functional differences in the amygdala. Yang et al. (2009) found an 18 percent reduction in the volume of the amygdala in a group of psychopaths compared to nonpsychopaths. Reduced functioning of the amygdala has also been observed in psychopathic individuals, particularly when they are presented with stimuli that are thought to invoke social emotions, such as during an affect recognition task (Gordon et al., 2004), during a socially interactive game (Rilling et al., 2007), and during the processing of emotional stimuli (Kiehl et al., 2001). In one study, brain functioning during the process of moral decision-making was examined. Individuals scoring higher in psychopathy demonstrated less functioning in the amygdala, particularly when contemplating hypothetical moral dilemmas involving direct harm to another individual (Glenn et al., 2009b). Research suggests that deficits in the amygdala may exist early in life and therefore may affect the process of moral socialization. Brain imaging studies in youth with callous-unemotional traits, which are thought to be analogous to psychopathic traits in adults, have found reduced functioning in the amygdala when viewing fearful facial expressions (Jones et al., 2009; Marsh et al., 2008).

The inability to take the emotional perspective of others may also result from deficits in the orbitofrontal/ventromedial region of the prefrontal cortex. The orbitofrontal cortex is important in understanding the emotional states of others (Shamay-Tsoory et al., 2005) and has been found to be active in several brain imaging studies presenting morally relevant stimuli (e.g., Borg et al., 2006; Harenski \& Hamann, 2006; Moll et al., 2002; Robertson et al., 2007). Furthermore, patients with damage to the orbitofrontal region demonstrate altered patterns of moral decisionmaking (Koenigs et al., 2007; Ciaramelli et al., 2007). Two studies have found reduced gray matter in the orbitofrontal cortex in psychopathic individuals (de Oliveira-Souza et al., 2008; Yang et al., 2009). Reduced functioning in this region has also been observed in individuals demonstrating higher levels of psychopathic traits during a social interactive game, and during emotion-related tasks (Gordon et al., 2004; Muller et al., 2003; Schneider et al., 2000). Reduced activity in the ventromedial prefrontal cortex has also been observed in criminal psychopaths when evaluating pictures of moral violations (Harenski et al., 2010).

Together, these findings suggest that in psychopaths, regions of the brain that are important in emotional processing are compromised, 
resulting in a diminished ability to empathize and recognize the suffering of others. This means that they are less responsive to one of the primary reasons that most individuals consider when making moral decisions.

\section{A lack of fear of the negative consequences of immoral behaviors}

In some situations, the emotions of a particular victim may not be salient, but individuals may still be deterred from committing immoral acts because of a fear of being caught and/or the negative consequences (e.g., paying a fine or being arrested) that may result from their actions. Psychopaths, however, demonstrate deficits that suggest that they are markedly less responsive to the types of cues that would generate this anxiety regarding being caught. For example, psychopathic murderers fail to show the normative increase in heart rate upon viewing emotion-provoking pictures. Psychopathic individuals also demonstrate reduced physiological responses to a number of stimuli, including imagined threat scenes (Patrick et al., 1994) and anticipated threat (Hare 1965, 1982; Hare et al., 1978; Ogloff \& Wong, 1990). They also demonstrate poor fear conditioning (Flor et al., 2002; Hare \& Quinn, 1971), meaning that they have difficulty learning to associate a particular cue with a negative event (e.g., punishment). Finally, one of the most robust findings in the psychopathy literature is that psychopaths fail to show the augmented startle response that most individuals show after exposure to threatening or anxiety-provoking stimuli. These studies suggest that psychopaths may not have the same internal signals that deter most individuals from engaging in acts that violate the law.

Deficits in fearfulness of negative stimuli have also been linked to deficits in the amygdala. Birbaumer et al. (2005) found that psychopathic individuals had reduced functioning in the amygdala during a fearconditioning task in which participants learn to associate a particular cue with an aversive stimulus. Deficits in fear conditioning may be present at a very early age. In a longitudinal study, Gao et al. (2010) found that poor fear conditioning at age 3 was associated with criminal offending at age 23. Similarly, in a 25 -year longitudinal study, Glenn et al. (2007) found that adults who demonstrated more psychopathic traits at age 28 had less of a fearful temperament at age 3.

The ability to shift behavior away from reward-seeking and attend to peripheral cues (e.g., the suffering of others or the threat of being caught) that signal that the behavior should be discontinued

In addition to affective deficits in fear and empathy, psychopaths have also been found to have cognitive deficits in attention that may impair 
their ability to process the relevant cues. For example, in neuropsychological tasks psychopathic individuals are able to avoid monetary punishment if that is their only goal. However, if the task also involves a goal of earning monetary rewards, it seems that reward becomes their primary goal and they are unable to perceive and recognize peripheral signals indicating that they should change their behavior (Newman \& Kosson, 1986). This type of cognitive deficit may lead to the reduced processing of information such as distress cues that promote empathy, or cues of threat or punishment that serve as important guides for behavior. The inability to pick up warning cues may significantly impair their ability to alter their course of action.

In addition to contributing to the affective deficits described in the previous sections, poor functioning in the prefrontal cortex may also contribute to the cognitive inability to attend to relevant stimuli. The orbitofrontal cortex is involved in processing reward and punishment information (Rolls, 2000) and inhibiting responses (Vollm et al., 2006). Patients with damage to the orbitofrontal cortex demonstrate impulsivity, poor planning, and disinhibited behavior (Damasio et al, 1990). As mentioned above, psychopaths have been found to demonstrate both structural and functional deficits in this region.

The inability to alter behavior may also stem from an increased sensitivity to reward in psychopathic individuals. Psychopathic traits have been associated with higher scores on behavioral approach and reward sensitivity (Wallace et al., 2009). On neuropsychological tests such as the Iowa Gambling Task, psychopathic individuals tend to make choices yielding large rewards but with more severe penalties (Blair et al., 2001; Mitchell et al., 2002). Brain imaging studies have also revealed increased functioning and volume of the striatum, a region of the brain involved in reward processing. Buckholtz et al. (2010) found that the impulsive-antisocial traits of psychopathy were associated with greater release of the reward-related neurotransmitter dopamine in the striatum in response to the administration of amphetamine. These traits were also associated with increased activity in the striatum during the anticipation of monetary reward. Two studies have observed increased volume in the striatum in individuals with psychopathic traits (Glenn et al., 2010; Schiffer et al., 2011).

Overall, the research presented above suggests that because of underlying neurobiological differences from normal individuals, psychopaths appear to lack responsiveness to many of the reasons that motivate individuals to behave morally. Much of this lies in core deficits in emotional processing - deficits which are not only observed in selfreports and observation of behavior, but which can be detected using 
physiological measures and brain imaging. Cognitive deficits in the processing of information may also contribute to impaired moral decisionmaking by increasing attention toward salient rewards and reducing attention to cues of punishment or cues that another is in distress. As we see in patients with damage to the orbitofrontal cortex who demonstrate both cognitive (poor planning, impulsivity) and affective (lack of empathy, emotional blunting) deficits, the same brain regions may influence both of these processes. A likely possibility is that cognitive and affective systems are highly dependent on one another, and are both necessary for proper moral development (Kennett, 2006). Indeed, a recent review on the neurobiology of morality concludes that it is most plausible to depict moral processes as requiring the engagement of both emotional and cognitive neural networks (Pascual et al., 2013). Longitudinal research suggests that neurobiological differences likely exist very early in life in individuals with psychopathic traits as adults, suggesting that the ability to respond to reasons that motivate individuals to behave morally may be compromised at an early age.

\section{Discussion and future directions}

Reasons-responsive compatibilist views seem to argue for the absence of moral responsibility or at least diminished responsibility in psychopaths, due to the absence of the relevant kind of guidance control. According to Fischer and Ravizza (1998), an individual is not morally responsible for a particular behavior if we can show that the behavior in question "is attributable to a significant brain lesion or a neurological disorder" (p. 35) that deprives these individuals of the right kind of reasons-responsiveness. In those cases, one cannot argue that the individual possesses guidance control over his or her behavior because responsibility-undermining factors are at work. Whereas normal individuals with normal brains can be said to have the right kind of reasonsresponsiveness to be held morally responsible (Fischer \& Ravizza, 1998; Glannon, 2011), individuals with brain impairments do not have the capacity to choose and act freely if their brain impairments deprive them of the right kind of reasons-responsiveness (i.e., the capacity for regular reasons receptivity and weak reasons reactivity).

According to Fischer and Ravizza, although smart animals, children, and (some) psychopaths can be said to exhibit a certain pattern of responsiveness to reasons, they are nevertheless not ordinarily judged as morally responsible. Although they may have the cognitive ability to respond appropriately to instrumental or prudential reasons, they do not seem to possess the cognitive ability to be guided by moral demands. 
An appropriate pattern of responsiveness to moral reasons involves an ability to recognize that "other persons' claims give rise to moral reasons that apply to him" (Fischer \& Ravizza, 1998: 77). This entails that it is not sufficient to know that certain acts involve a moral transgression (e.g., that according to "society" it is morally wrong to do such and such action). One additionally needs to be able to identify moral reasons for or against a certain action as reasons that apply to oneself. If an individual lacks such a minimal receptivity to reasons, he or she fails to be a moral agent at all. On their view, smart animals, children and (some) psychopaths cannot be considered moral agents and should therefore not be held morally responsible.

Based upon the above-mentioned empirical findings, it appears that psychopaths, at the very least, suffer from an impaired responsiveness to moral reasons in such a way that these individuals may know that certain acts are wrong, but may nevertheless be unable to fully grasp, both affectively and cognitively, why these acts are wrong and therefore unable to translate this knowledge into morally appropriate action. In line with Kennett (2006), the empirical literature suggests that the moral impairments in psychopathy are due to a combination of both affective and cognitive deficits. Individuals with psychopathy suffer to a greater or lesser degree from impairments in emotional responsiveness (affective deficits in empathy and fear) and impairments in cognitive functioning (attention deficits and reward-processing deficits), which in combination may lead to greater or lesser abnormalities in moral rationality/decisionmaking. Although Fischer and Ravizza (1998) limit their account of reasons-receptivity to cognitive capacities, it seems most plausible to assume that affective capacities are involved as well (Pascual et al., 2013). Both affective and cognitive capacities are essential for proper moral development and are very likely neurobiologically and experientially interdependent (Greene et al., 2001; Greene \& Haidt, 2002; Kennett, 2006). On our view, an individual's receptivity and reactivity to moral reasons may be similarly interdependent. Although psychopaths may lack the necessary cognitive ability to be moved by moral demands, the empirical data suggest that psychopaths' affective deficits are central to their diminished (or absent) responsiveness to moral reasons. It appears that criminal psychopaths cannot "feel" the wrongness of their actions (or are impaired in this sense), which likely makes it impossible to adequately recognize moral reasons against such actions as reasons applying to themselves (i.e., as generating sufficient reasons for action), and to adequately react to moral reasons. In fact, it may be argued that in normal individuals, one's emotional responsiveness plays a major role both in the ability to identify with moral reasons as reasons applying to 
oneself and in the ability to react to moral reasons (Greene et al., 2001; Greene \& Haidt, 2002). Abnormalities in emotional responsiveness, in combination with and potentially aggravated by cognitive impairments, may result both in impaired receptivity and in impaired reactivity to moral reasons. Together, the empirical findings are in line with an impaired responsiveness to moral reasons in psychopaths driven by abnormalities in emotional responsiveness and cognitive decision-making. Hence, on Fischer and Ravizza's account and in line with the empirical findings outlined above, criminal psychopaths may be partially or fully excused based upon diminished or absent responsiveness to moral reasons.

Although we have restricted our analysis to reasons-responsiveness compatibilist views, we briefly want to touch upon Frankfurt's hierarchical "mesh theory" account of free will and moral responsibility (Frankfurt, 1971). According to Frankfurt, moral responsibility requires that an individual's behavior is motivated by or originates from his or her second-order identification with his or her first-order desire to act in a certain way. Surely, psychopaths can be regarded as having the capacity to identify with their desires. Are they morally responsible after all? Frankfurt's view can be described as a hierarchical "mesh theory," in which moral responsibility depends on an appropriate "mesh" between one's behavior and one's true self. If an individual's behavior and the desires that function as motives for his or her behavior reflect how he or she wishes to be, then he or she can be considered morally responsible. The problem with this kind of mesh theory is the dependence of moral responsibility on one's psychological functioning at a particular moment in time. It does not seem to matter how an individual's psychological functioning came about or why it is the way it is. Fischer and Ravizza (1998) rightly criticize Frankfurt's mesh theory as incomplete because it does not account for the possibility of (prior) responsibility-undermining factors that may impact the psychological mechanisms (i.e., the processes that underlie human decision-making and behavior) by which an individual's current psychological functioning comes about. Fischer and Ravizza (1998) argue that such responsibility-undermining factors may potentially be identified in the case of psychopaths. It is likely that the normative power of reasons draws upon the normal functioning of both affective and cognitive processes involved in moral decision-making. The empirical data presented above suggests that individuals with psychopathy are to a greater or lesser extent impaired in each of these domains of normal psychological functioning. Moreover, if we consider psychopathy to be a neurodevelopmental psychiatric disorder (Gao et al., 2009; Rutter, 2012), the identification of the precursors to these traits early in life may lead to effective intervention that might prevent a person from 
developing psychopathy in adulthood. This may be key to successful crime prevention in adult life (Glenn \& Raine, 2014).

Under current US criminal law there are two generic excusing conditions: lack of rational capacity and compulsion. Compulsion can be either externally (e.g., threats) or internally (i.e., strong internal desires) manifested (Morse, 2011b). Drawing upon a human rights-based framework, offenders who do not satisfy the required rationality criteria for legal culpability and who are not deemed legally responsible should not be sentenced and should instead receive adequate mental health treatment that may or may not involve involuntary civil commitment. Of course, with respect to psychopathy, a major challenge will be determining which individuals should be held responsible and which individuals should be excused. Psychopathic traits exist on a continuum in the population, as do many of the neurobiological deficits that we observe. The unfortunate truth is that attempting to draw a firm line between responsibility and non-responsibility will be futile (Eagleman, 2011). What we should take away from the neurobiological research on psychopathy is that not all individuals have the same capacity for making moral decisions. Rather than focusing on punishment of the individual who may have had limited capacity to behave morally, we should greatly increase our emphasis on rehabilitation efforts, while at the same time ensuring that society is protected, and that the feelings and the rights of victims are acknowledged. As outlined above, such an approach is in line with hard determinist, hard incompatibilist, and compatibilist views (e.g., Fischer \& Ravizza, 1998; Greene \& Cohen, 2004; Wolf, 1990) on free will and moral/criminal responsibility.

For example, the Netherlands allows for post-prison mandated mental health treatment, either residential or non-residential, of mentally ill offenders provided that such treatment has been deemed necessary at the time of sentencing. For non-violent crimes the maximum duration entails four years after the offender has completed his or her prison sentence. For violent crimes, the duration may be extended if certain conditions are met. Such post-prison treatment, possibly involving nonresidential treatment, might provide a better "solution" for individuals with mild to moderate psychopathy compared to a prison sentence without any type of treatment at all (e.g., neurofeedback, cognitive behavioral therapy with or without psychopharmacological treatment, neurocognitive training, nutritional interventions). In comparison, for certain severe and violent psychopathic offenders it will not be warranted from a public safety perspective to release these individuals back into society and may thus result in very long or even lifelong civil commitment. Hence, for certain severe and violent psychopathic offenders, 
getting a prison sentence will likely lead to an earlier release compared to civil commitment. At the same time, giving these individuals a long prison sentence without any kind of treatment is problematic from the standpoint of public safety (these individuals will re-enter society at some point), as well as from the standpoint of offenders' human rights. Individuals with mental health disorders, including individuals with psychopathy, have a basic human right to receive adequate mental health treatment whether these individuals are offenders or law-abiding citizens.

Interestingly, affective and cognitive deficits and their underlying neurobiological abnormalities may potentially be addressed by modulating abnormal brain activation using fMRI neurofeedback (i.e., conditioning the brain areas involved to function differently). fMRI neurofeedback research in criminal psychopaths is currently focusing on the impaired fear system in psychopathy that comprises the orbitofrontal cortex, the amygdala, the anterior cingulate cortex (ACC), and the insula. The aim of the feedback is to increase the activity in those areas of the brain that form the fear-system in normal individuals, and to induce brain growth since these areas are typically reduced in volume in individuals with psychopathy compared to normal controls. In an ongoing study, Sitaram and colleagues have shown that offenders with psychopathy can learn to regulate their left anterior insula based upon a combination of emotional episodic memories and contingent feedback, which was found to increase the causal density (number of connections) in their emotional brain network and increase the causal flow (difference between ingoing and outgoing connections) of their left insula (Sitaram 2007; Sitaram et al., 2009). Although highly experimental at present, this kind of research might provide us with effective treatment options for psychopathy in the future - hence, the need to discuss the ethical desirability of offering such neurotechnological or other sufficiently benign biosocial treatments to offenders either as an alternative to incarceration or requirement for probation and/or parole (Bublitz \& Merkel, 2014; Focquaert, 2014).

\section{REFERENCES}

Adolphs, R., Tranel, D., Hamann, S., Young, A. W., Calder, A. J. et al. (1999). "Recognition of facial emotion in nine individuals with bilateral amygdala damage." Neuropsychologia 37: 1111-1117.

Birbaumer, N., Veit, R., Lotze, M., Erb, M., Hermann, C. et al. (2005). "Deficient fear conditioning in psychopathy: a functional magnetic resonance imaging study." Archives of General Psychiatry 62: 799-805.

Blair, R. J., Colledge, E., Murray, L., and Mitchell, D. G. (2001). "A selective impairment in the processing of sad and fearful facial expressions in 
children with psychopathic tendencies." Fournal of Abnormal Child Psychology 29: 491-498.

Blair, R. J., Colledge, E., and Mitchell, D. G. V. (2001). "Somatic markers and response reversal: is there orbitofrontal cortex dysfunction in boys with psychopathic tendencies." Fournal of Abnormal Child Psychology 29: 499-511.

Blair, R. J. R., Mitchell, D. G. V., Peschardt, K. S., Colledge, E., Leonard, R. A., et al. (2004). "Reduced sensitivity to others' fearful expressions in psychopathic individuals." Personality and Individual Differences 37(6): 1111-1122.

Blair, R. J. R., Budhani, S., Colledge, E., and Scott, S. (2005). "Deafness to fear in boys with psychopathic tendencies." fournal of Child Psychology and Psychiatry 46(3): 327-336.

Borg, J. S., Hynes, C., Horn, J. V., Grafton, S., and Sinnott-Armstrong, W. (2006). "Consequences, action, and intention as factors in moral judgments: an fMRI investigation." Fournal of Cognitive Neuroscience 18: 803-817.

Bublitz, J. C., and Merkel, R. (2014). "Crimes against minds: on mental manipulations, harms, and a human right to mental self-determination." Criminal Law and Philosophy 8: 51-77.

Buckholtz, J. W., Treadway, M. T., Cowan, R. L., Woodward, N. D., Benning, S. D., Li, R., et al. (2010). "Mesolimbic dopamine reward system hypersensitivity in individuals with psychopathic traits." Nature Neuroscience 13: 419-421.

Ciaramelli, E., Muccioli, M., Làdavas, E., and di Pellegrino, G. (2007). "Selective deficit in personal moral judgment following damage to ventromedial prefrontal cortex." Social, Cognitive and Affective Neuroscience 2: 84-92.

Clarke, R. (2000) “Modest libertarianism.” Philosophical Perspectives 14: 21-45.

Damasio, A. R., Tranel, D., and Damasio, H. (1990). "Individuals with sociopathic behavior caused by frontal damage fail to respond autonomically to social-stimuli." Behavioural Brain Research 41(2): 81-94.

de Oliveira-Souza, R., Hare, R. D., Bramati, I. E., Garrido, G. J., Azevedo, Ignácio F., et al. (2008). "Psychopathy as a disorder of the moral brain: fronto-temporo-limbic grey matter reductions demonstrated by voxel-based morphometry." NeuroImage 40: 1202-1213.

Dennett, D. (2003). Freedom Evolves. Penguin Books.

Eagleman, D. (2011). "The brain on trial." Atlantic Monthly 308: 112-123.

Farah, M. (2005). "Neuroethics: the practical and the philosophical." Trends in Cognitive Sciences 9: 34-40.

Fischer, J. M., and Ravizza, M. (1998). Responsibility and Control: A Theory of Moral Responsibility. Cambridge University Press.

Flor, H., Birbaumer, N., Hermann, C., Ziegler, S., and Patrick, Christopher J. (2002). "Aversive Pavlovian conditioning in psychopaths: peripheral and central correlates." Psychophysiology 39: 505-518.

Focquaert, F. (2014). "Mandatory neurotechnological treatment: ethical issues." Theoretical Medicine and Bioethics 35: 59-72. DOI 10.1007/s11017-0149276-6 